\title{
EDITORIAL
}

\section{MEDICAL NEGLIGENCE AND MALPRACTICE LITIGATIONS IN SRI LANKA: WHY IT IS A TIP OF AN ICEBERG?}

\section{Induwara Gooneratne}

\section{Department of Forensic Medicine, University of Peradeniya, Sri Lanka}

Many have raised their eye brows at the alarming number of medical malpractice, negligence and medical errors that occur daily world over. Despite advances in medicine, cases of medical negligence and malpractice seem unavoidable. Majority of such cases are attributed to personal negligence, recklessness or wilful blindness of the practitioner. Indeed, the development of law especially the common law related to handling emerging challenges arise with medical malpractice seem to curtail the purported damages that can be faced by people in many countries. However, ironically neither the law nor the jurisprudence in Sri Lanka appear to proactively engage in solving issues related to medical negligence and malpractice.

While many developed countries evidently maintain the significance of highlighting medical malpractice as a social issue, Sri Lanka, on the contrary surfaces a rather lethargic or silent attitude on the issue of medical malpractice. Of course there are a few cases brought up in daily news and media coverage but unfortunately they do not all reach legal remedies or justice due to numerous reasons. Given the significant number of incidence of adverse events and negligence in developed countries for example in the USA as illustrated by Harvard study (1991), in the UK (Goldberg, 2011) and Australia (Bismark, 2013) one could reasonably assume that Sri Lanka could have much more than what is reported in the west. The reality is that the reported cases of negligence in medical practice are just a tip of an iceberg. This paper therefore attempts to argue reasons for the under reporting of medical negligence and malpractice issues in Sri Lanka.

First of all we in Sri Lanka do not have a system to register, maintain and follow up medical litigation cases. It will be a good idea to implement a centralized registry in the ministry of health where all complaints and litigations regarding medical care are required to be registered. A designated officer from this registry will have the responsibility to follow up and feed new details of all cases and complaints as to what has taken place regarding the incidents. A process of this nature will not only help to identify root causes for such errors or malpractice so that they can be used in policy reforms but also they will be useful resource for research. 
Noting the under reported cases of medical negligence, ignorance among general public on medical aspects remain a major attribute to under reporting of negligence cases. The closed system in Sri Lanka is such that the information regarding the patient is not easily accessible to the patient or the family. There is no one in the ward set up or in the clinic set up to ask details. Busy doctors have loads of patients to clear up in the busy clinics or wards. Of course most medical practitioners have a private practice, so that it is likely that they want to spend as less time as possible in the state set up to save time and energy for the private practice. Most practitioners are blamed for lack of communication skills. This reason avoids patients receiving detailed information. On the other hand even if patients receive information, it is unlikely that most will understand the contents of it.

The public belief that the hospital or the medical staff will always do the best for the patient seems to still exist in Sri Lanka. This means that patients will entirely trust the medical team. Notwithstanding such bestowed trustworthiness upon practitioners, many seem to speculate now that the medical staff too can err or mistake. In the face of such changes in belief, it is apparent that there is a growing demand of speculation and skepticism about medical management at present.

Having considered ignorance of many on matters related to medicine and its practice and the heightened trust placed upon the medical staff, it is now important to highlight the symbolic posture society has placed on health and the health care practitioners. Certainly the roots of an elevated symbolism on medical profession is grounded on the value society has on human life. Simply, this symbolism explains the value enshrined upon those who are trained or to care for the sick to alleviate pain and regain life. In the same vein, the extrapolated social symbolism constructed on the health care profession, coupled with the finances they earn posits the practitioner in a socially elevated position, which in turn allows development of an assumed power structure within the person as well as in the profession. This creates a power imbalance especially between the poor and the professionals which then can end up in the poor 'giving in' to the power, despite their gut feeling of an injustice or malpractice.

An equally important aspect to consider is the lack of alternatives other than a court process for medical malpractice cases. Of course, there can be institutional inquiries and inquiries at Sri Lanka Medical Council level, however the use of these also are limited. But, we can consider alternate dispute resolutions or mediations for suitable cases. The expense parties have to bear and the legal costs and the length of time taken to conclude civil cases in courts are other reasons for reluctance among people to take actions against medical negligence.

Certainly, some people may refrain from taking action although they feel there was negligence especially in the public health sector, because the provision of health they received was free. They may feel reluctant or rather uncomfortable to go against the people who treated their loved one free of charge. It is however important to note that the medical staff is working for a salary and that they have a responsibility 
to the patient as well as to the state who pays them to perform with good standards and quality. Noting the compelling nature of any such irregularity or negligence by a health care practitioner, many fear to make allegations in public or to responsible bodies. The central concern with this fear is associated with possible revenge from the medical staff when they or their relative come for treatment next time.

Despite the loss people may have experienced, some may tend to think that it is useless trying as either the loved one is already demised or the body part is already taken off. Proponents of this view will opine that a compensation in the form of money will not make an equitable compensation, for example replacing the lost loved one. Others may attribute the loss to 'karma' or fate. People have fear that even the court system will favour the medical staff. Considering the close connections they may have or undisclosed duress they may have being patients the selves of the alleged doctor, it is possible that people will speculate some biasness towards the powerful professions. Nonetheless, some may accept that the staff had made a mistake without any inquiry.

While medical negligence and malpractice are considered to be important social issues in many countries, Sri Lanka as shown above does not seem to be very much concerned with malpractice litigation, of course due to many reasons out of which some have been highlighted above. 